\title{
Working time flexibility and work-life balance
}

\section{The role of segmentation preference}

\author{
Anne M. Wöhrmann ${ }^{1} \cdot$ Nicola Dilchert ${ }^{2} \cdot$ Alexandra Michel $^{1}$ \\ Published online: 6 October 2020 \\ (c) The Author(s) 2020
}

\begin{abstract}
Based on border theory (Clark 2000), we aim to investigate the relationship between individual-oriented and organization-oriented working time flexibility and employees' work-life balance, as well as the moderating role of segmentation preference. We use data from around 18,000 employees from the 2015 Working Time Survey of the Federal Institute for Occupational Safety and Health in Germany. Survey data were collected through computer-assisted telephone interviews. Hierarchical regression analysis revealed that individual-oriented working time flexibility was positively related to employees' work-life balance, whereas organization-oriented working time flexibility had a negative effect. Employees' individual preferences regarding the segmentation of work and private life only played a minor role. Those with a higher segmentation preference profit only marginally more from individual-oriented working time flexibility and suffer only marginally more from organization-oriented working time flexibility demands.

Practical Relevance: Taken together, the study's findings highlight the importance of the design of flexible working time arrangements for improving employees' work-life balance. Employers should grant their employees a certain degree of working time autonomy while keeping organization-oriented working time requirements, such as changes of working time at short notice to accommodate operational demands, to a minimum. This applies to all employees, not only those with a strong preference for separating work and private life.
\end{abstract}

Keywords Border theory $\cdot$ Segmentation preference $\cdot$ Work-life balance $\cdot$ Working time flexibility $\cdot$ Working time control

Dr. Anne M. Wöhrmann

woehrmann.annemarit@baua.bund.de

1 Bundesanstalt für Arbeitsschutz und Arbeitsmedizin (BAuA), Friedrich-Henkel-Weg 1-25, 44149 Dortmund, Germany

2 Universität Heidelberg, Hauptstr. 47-51, 69117 Heidelberg, Germany 


\section{Arbeitszeitflexibilität und Work-Life-Balance}

Die Rolle der Segmentationspräferenz

\section{Zusammenfassung}

Basierend auf der Border Theory (Clark 2000) ist das Ziel dieser Studie, den Zusammenhang zwischen individuumsbezogener und betriebsbezogener Arbeitszeitflexibilität mit der Work-Life-Balance sowie die Rolle der Präferenz für die Trennung von Arbeit und Privatleben für diesen Zusammenhang zu untersuchen. Wir verwenden Daten von rund 18.000 abhängig Beschäftigten aus der BAuA-Arbeitszeitbefragung 2015 der Bundesanstalt für Arbeitsschutz und Arbeitsmedizin. Die Befragungsdaten wurde mit Hilfe von computergestützten Telefoninterviews erhoben. Die Regressionsanalysen zeigen, dass die individuumsbezogene Arbeitszeitflexibilität positiv und die betriebsbezogene Arbeitszeitflexibilität negativ mit der Work-Life-Balance der Mitarbeiter zusammenhängt. Die individuellen Präferenzen der Mitarbeiter in Bezug auf die Trennung von Arbeit und Privatleben spielen dabei nur eine untergeordnete Rolle. Wer eine höhere Segmentationspräferenz hat, profitiert nur unwesentlich mehr von der individuumsbezogenen Arbeitszeitflexibilität und leidet auch nur unwesentlich stärker unter betriebsbezogenen Arbeitszeitflexibilitätsanforderungen.

Praktische Relevanz: Zusammengenommen weisen die Ergebnisse der Studie auf die Bedeutung der Gestaltung von flexibler Arbeitszeit für die Vereinbarkeit von Beruf und Privatleben der Mitarbeiter hin. Während die Arbeitgeber ihren Mitarbeitern in gewissem Umfang Arbeitszeitautonomie einräumen sollten, sollten sie den organisationsbezogenen Arbeitszeitbedarf im Hinblick auf kurzfristige Arbeitszeitänderungen aufgrund betrieblicher Anforderungen für ihre Mitarbeiter auf ein Minimum beschränken. Dies gilt für alle Mitarbeiter und nicht nur für diejenigen, die eine starke Präferenz für die Trennung von Beruf und Privatleben haben.

Schlüsselwörter Border Theory · Segmentationspräferenz · Work-Life-Balance · Arbeitszeitflexibilität ·

Arbeitszeitautonomie

\section{Introduction}

Current trends in the working world such as globalization, digitalization, and changing values result in the need for employees and organizations to become more and more flexible. Flexible working time models, weekend work, and overtime work enable organizations and their employees to be available for the global customer at any time. Thus, the flexibility requirements of organizations translate into flexibility requirements for employees. In contrast to this organization-oriented working time flexibility, which results in nonstandard schedules, changes in the working world also allow for more individual-oriented working time flexibility, that is, the possibility for employees to have some autonomy in determining their working time (Costa et al. 2004). Further, there is evidence that individual-oriented and organization-oriented working time flexibility are related to worklife balance, health, and well-being of employees (Kossek and Michel 2011).

One of today's key challenges is to reconcile new developments in the working world with employees' work-life balance. Diminishing boundaries between work and private life as a result of working time and workplace flexibility have triggered research on employees' preferences regarding the segmentation or integration of life domains (Ammons 2013). While it has repeatedly been found that behavior aimed at the segmentation of work and private life domains is related to favorable work-life outcomes (e.g.,
Kreiner 2006; Michel et al. 2015; Rexroth et al. 2017), research on segmentation preferences is not that consistent. Findings so far suggest that segmentation preferences are not directly related to work-life outcomes-except for psychological work-family conflict, indicating a preoccupation with one role while being in the other (Allen et al. 2014; Park and Jex 2011). However, emerging research indicates that segmentation preference as a personal attitude may affect the extent to which working conditions are related to aspects of work-life balance. For example, Derks et al. (2016) found that smartphone use is related to reduced work-family conflict for employees preferring integration (integrators) but not for employees preferring segmentation (segmenters).

This study aims to shed light on how organization-oriented working time flexibility and individual-oriented working time flexibility are related to employees' work-life balance. Based on border theory (Clark 2000) and the workhome resources model (ten Brummelhuis and Bakker 2012), we aim to capture the relevance of segmentation preference as an individual attitude regarding the extent to which individual-oriented and organization-oriented flexibility affect employees' work-life balance. We thereby contribute to a more nuanced understanding of the role of flexible work arrangements and their different meanings for employees who prefer a segmentation or integration of work and home. The conceptual model is depicted in Fig. 1. We examine these relationships in a large-scale representative 
Fig. 1 Conceptual model

Abb. 1 Konzeptionelles Modell

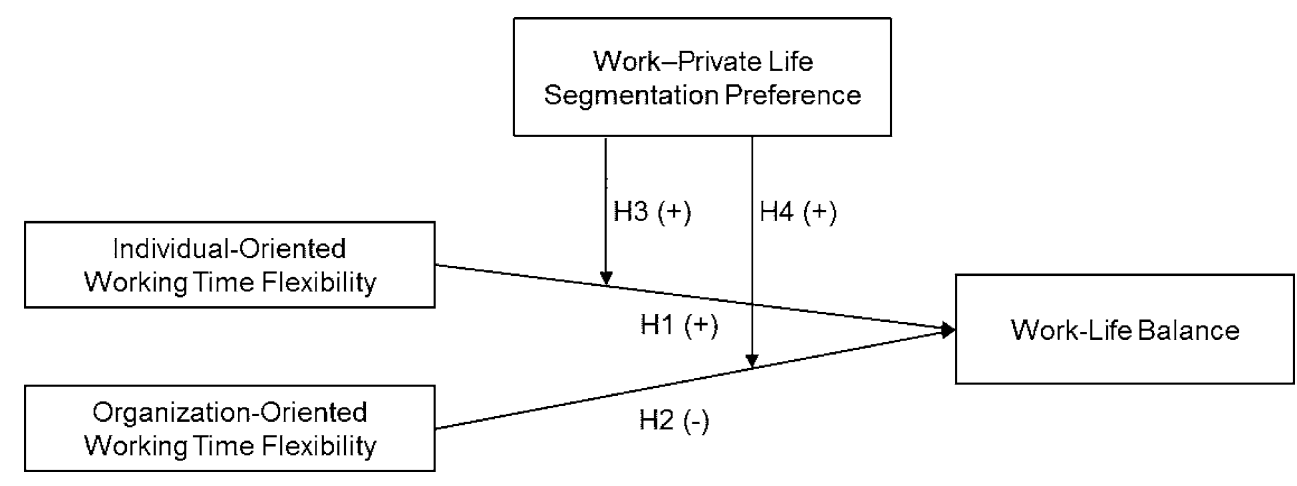

sample by using national survey data from German employees to provide findings that are generalizable to the majority of the German workforce, across all industries and occupations. Accordingly, the practical implications of this study may find wider application.

\section{Working time flexibility and work-life balance}

Work-life balance can be defined as an individual's emotional and cognitive evaluation of their satisfaction with the fit of work and private life (Valcour 2007). A good worklife balance is beneficially related to health and work outcomes. For example, in a scoping review, Wöhrmann (2016) found well-being (e.g., life satisfaction), mental problems (e.g., symptoms of fear and depression), work-related mental problems (e.g., exhaustion and irritation), and general health status, as well as attitudes towards work and the organization (e.g., work satisfaction, commitment, and turnover) to be related to employees' work-life balance. Although the outcomes of work-life balance have not been studied that extensively, there is a large body of literature, including several meta-analyses and systematic reviews, showing that work-family conflict, a construct closely related to worklife balance, is related to health and work outcomes (e.g., Allen et al. 2000; Amstad et al. 2011; Michel et al. 2009; Nohe et al. 2015; for an overview see Wöhrmann 2016). Thus, the fit of work and private life is not only important for the well-being of employees; it can also affect organizations through employees' higher likelihood of sickness absence (e.g., Nilsen et al. 2017), turnover intentions, and decreased engagement or performance (e.g., Amstad et al. 2011).

An important aspect for a good work-life balance is the time available for private life. This time is determined by employees' working time arrangements. For example, a cross-national study (Lunau et al. 2014) showed that between-country variations in work-life balance can partly be explained by working hours and working time regulations.
An important aspect in this regard is also the flexibility of working time. National contexts as well as organizational contexts may factor into how flexible working time affects employees' work-life balance (Chung and van der Lippe 2018). If employees can decide when and how long they work, they have control over their working time. Thus, flexibility is highly available to them (Matthews and BarnesFarrell 2010). In the current study, we refer to this type of working time flexibility as individual-oriented working time flexibility.

Individual-oriented working time flexibility enhances employees' perceived ability to control the boundaries between their work and private-life roles. According to border theory (Clark 2000), these borders or boundaries can be temporal, spacial, or psychological, and they are defined by their permeability and flexibility. Providing employees with autonomy to alter their boundaries provides a work resource. According to ten Brummelhuis and Bakkers' (2012) work-home resources model, which is rooted in conservation of resources theory (COR; Hobfoll 1989), contextual resources, such as autonomy, which is also described as a work resource, can help build up and retain personal resources. These can be classified into physical (e.g., energy), psychological (e.g., mental resilience), affective (e.g., mood), intellectual (e.g., skills), and capital (e.g., time) resources. These personal resources in turn affect employees' work-life balance. For example, flextime, which gives employees some control over their daily start and end times at work, is a means to shift the border between work and home according to personal needs. For instance, some employees might use this form of individual-oriented flexibility to tailor their working hours to their preferred time of waking up in the morning, making them more energetic and good-humored during the day. Others might leave work early on certain days, for example to take care of children or to engage in leisure activities, thereby raising their mood and energy level and allowing for a better allocation of time to work and private life. It has to be noted, however, that a high level of working time autonomy, leaving employees entirely free to choose 
their working hours, may have disadvantageous effects on employees' private lives (e.g., Lott 2018; Seitz and Rigotti 2018). Especially when combined with high work intensity or pressure, working time autonomy may facilitate worklife conflict and self-endangering behaviour such as the unhealthy extension of working hours (e.g., Hünefeld et al. 2019; Lott 2017). In particular, working time autonomy, if introduced as part of a high-performance strategy, is related to overtime work. However, overtime does not increase significantly if employees get more control over their work schedule to enhance their work-life balance (Chung and van der Horst 2020).

Several studies have shown that individual-oriented working time flexibility can have a positive effect on worklife balance (e.g., Njip et al. 2012). In addition, the psychological experience of having control over one's working time is associated with feelings of general well-being and satisfaction (Deci et al. 2001). This feeling can in turn increase satisfaction in various areas of life. Thus, individual-oriented working time flexibility, for example in the form of decision latitude over the daily start and end time of work (Costa et al. 2004), can serve as an important contextual resource to support work-life balance, because it is positively related to the ability to meet different role requirements (Kossek et al. 2006). Thus, building on previous empirical findings and in line with the work-homeresources model (ten Brummelhuis and Bakker 2012), we expect:

Hypothesis 1: Individual-oriented working time flexibility is positively related to work-life balance.

In contrast, organization-oriented working time flexibility restricts employees' perceived control over the timing of their work and thus over the boundaries between work and private life. As opposed to individual-oriented working time flexibility, organization-oriented working time flexibility is a work demand employees have to cope with. Organizationoriented working time flexibility, which requires employees to flexibly adjust their working hours to the employer's needs, may affect the variability of working time (e.g., having to be available at short notice; Janßen and Nachreiner 2004) but also the duration (e.g., working overtime) and timing of work (e.g., working at unusual hours). These components of working time have an immediate effect on employees' everyday life. Working time requirements determine how much time is left for social obligations, family, leisure, and recreation (Costa et al. 2004). The various effects of different aspects of working time demands on employees' work-life balance have been widely studied. For example, both McNamara et al. (2013) and Edwards and Rothbard (2000) investigated the impact of long working hours on work-life balance, finding that longer working hours are related to an inferior work-life balance. Greubel et al. (2016) found evening, Saturday, and Sunday work to increase the odds of an inferior work-life balance. In addition, the negative effects of working time variability, such as frequent changes in working hours (e.g., VahleHinz and Bamberg 2009), and employer-oriented flexible schedules have been documented (e.g., Lott 2018). In sum, research suggests that working time flexibility that affects the duration, location, and variability of working time may have a negative impact on work-life balance. According to the work-home resources model, high temporal flexibility requirements such as overtime or weekend work not only consume personal resources (e.g., time and energy) but also keep people from building new personal resources (ten Brummelhuis and Bakker 2012). This negative effect of organization-oriented working time flexibility on personal resources can in turn lead to a worse work-life balance, because less time and energy are left for personal needs in other roles, which in turn reduces employees' satisfaction with how well they meet the requirements in all roles (Valcour 2007). For example, having to work overtime at short notice might force employees to cancel private appointments for lack of time. Further, the lack of energy after an unexpectedly long day at work could keep employees from spending quality time with their partners and children, thereby putting a burden on family life as well. Therefore, we expect the following:

Hypothesis 2: Organization-oriented working time flexibility is negatively related to work-life balance.

\section{Segmentation preference}

Above, we hypothesize that working time flexibility-depending on who controls the boundaries (individualoriented vs. organization-oriented working time flexibility)_is directly related to work-life balance. However, employees' individual attitudes towards the boundaries between work and private life may also be relevant in this context. According to boundary theory, individuals differ in their preferences for separating or integrating work and private life (Ashforth et al. 2000; Rothbard et al. 2005; Kreiner et al. 2009; Nippert-Eng 1996). On a continuum, individuals with a high segmentation preference have a strong desire to separate work and private life domains, whereas individuals with a low segmentation preference like to integrate different life domains (Nippert-Eng 1996). Thus, taking a person-environment fit perspective, some forms of boundary management may be more suited for integrators, whereas others are better for segmenters (Ashforth et al. 2000; Kreiner et al. 2009). 
Individual-oriented working time flexibility, and hence the ability to control the boundaries between work and private life, enables employees to enact the boundary management strategy they prefer. Segmentation preferences themselves are not directly related to work-life balance, but work-life balance may depend on the fit between preferences regarding segmentation or integration and actual contextual conditions (Allen et al. 2014; Kreiner 2006; Peters et al. 2014). Some studies have already considered segmentation preference as a moderator of the work-life interface (Derks et al. 2016). For example, Rothbard et al. (2005) found that when they had access to flextime, segmenters had a higher job commitment than integrators. Therefore, the effect of individual-oriented and organization-oriented working time flexibility on work-life balance may to a certain extent depend on individuals' attitudes in terms of their segmentation preference.

Rothbard et al. (2005) argue that flextime is more of a segmentation-related strategy than an integration-related strategy, because it helps people to keep up spatial and temporal boundaries between work and private life. Thus, for those with strong segmentation preferences, having the possibility to move temporal boundaries may be especially important, because this helps them maintain the boundaries between work and private life. For example, segmenters may find the possibility to spend an extra hour at work to wait for an issue to be resolved preferable to taking work calls later during their free time. Likewise, being able to leave work early to take care of a private issue, such as helping one's child with a problem, is preferable to dealing with private matters at work, for instance by calling others for help or having to tell the supervisor or colleagues about private matters. If segmenters do not have control over the timing of their work and hence lack the ability to enact their boundary management strategies, they may end up being irritated, stressed, or in a bad mood, which in turn may negatively affect their work-life balance.

Employees with a low segmentation preference might also benefit from individual-oriented working time flexibility, as it helps balance working hours and private life. Further, research has shown that the possibility to segment different life domains may reduce work-life conflict even among integrators (Kreiner 2006). Thus, flextime might also benefit the work-life balance of those with low segmentation preference by giving them a tool to use at their convenience. However, if a lack of individual-oriented working time flexibility leaves employees unable to control their work-life boundaries, those who do not particularly want to keep their different life domains apart might feel less stressed. For integrators, the blending of life domains itself does not have such a negative impact. Dealing with some private matters that come up during fixed working hours rather matches their preference for integrating life domains.
For segmenters, by contrast, a dissolution of boundaries represents an extra stressor that might drain their energy or impair their mood. Thus, taking a person-environment fit perspective and drawing on the theoretical assumptions of border/boundary theory, a lack of individual-oriented working time flexibility may have more adverse effects on segmenters than on integrators, because it may also represent an unpleasant loss of control over the permeability of boundaries. Therefore, we expect the following:

Hypothesis 3: Segmentation preference moderates the positive relationship between individual-oriented working time flexibility and work-life balance as follows: For employees with a high segmentation preference, the relationship is stronger than for those with a low segmentation preference.

Employees with a high segmentation preference find it important to maintain temporal, spatial, or psychological boundaries between work and private life domains. Organization-oriented working time flexibility may threaten the clear separation of work and private life and may therefore be especially demanding for segmenters. For example, short notice changes in working hours, which force a segmenter to organize private matters at work or to work from home on the weekend, disrupt the separation of work and private life. Integrators, by contrast, will not be affected as strongly in their work-life balance by flexible working time demands such as short notice changes to their working hours. Of course, their work-life balance also suffers if they have to cancel private appointments and have less time for recovery. But the intrusion of work into their private life, such as having to take work home for the weekend, may not be perceived as stressful, because it is in line with their attitude and their preference for blending experiences and cognitions of different life domains into one holistic experience (Kreiner 2006). Therefore, again from a person-environment fit perspective and drawing on the theoretical assumptions of border/boundary theory, organization-oriented working time flexibility, much like the lack of individual-oriented working time flexibility, should have a more negative effect on the work-life balance of employees who prefer to separate life domains.

Hypothesis 4: Segmentation preference moderates the negative relationship between organization-oriented working time flexibility and work-life balance as follows: For employees with a high segmentation preference, the relationship is stronger than for employees with a low segmentation preference. 


\section{Method}

\subsection{Sample and procedure}

For this study, we used data of the 2015 BAuA-Working Time Survey of the Federal Institute for Occupational Safety and Health (BAuA). In 2015, a random sample of 20,000 employees in Germany took part in computer-assisted telephone interviews (Häring et al. 2016). Several hundred professional interviewers of a social science research institute conducted the standardized interviews. The interviews lasted about 35 min and focused on employees' working time, but they also covered other topics such as working conditions, socio-demographics, employment, and organizational characteristics, as well as aspects of health and well-being. Participants were contacted through randomly generated telephone numbers. The survey population is comprised of individuals aged 15 or older who live in Germany and work at least $10 \mathrm{~h}$ a week in paid employment. With weights applied, the data are representative of this group of employees. In the current study, we used data of a subsample of 17,921 individuals in dependent employment up until the age of 65 . We thus excluded participants who were self-employed or older than 65 years. About half of the participants were men $(50 \%)$, and the average age was 46. Just over one-third (35\%) of respondents had children under the age of 18 living in the household. About half of the sample was highly educated (47\%). About onethird of the sample held a supervisory role (34\%), and $76 \%$ worked full time. The majority of respondents worked in the public sector $(33 \%)$ or in the service sector $(29 \%)$. Another $22 \%$ worked in industry and $9 \%$ in the crafts sector. Seven percent worked in other, non-specified sectors. We conducted a hierarchical moderated regression analysis with SPSS 26

\subsection{Measures}

Work-life balance: To measure work-life balance, we used a German translation of the following item from Valcour's (2007) scale for satisfaction with work-life balance: "How satisfied are you with how well your work life and your personal life fit together?" Using a single item to measure work-life balance is common in work-life balance satisfaction studies (Clarke et al. 2004; Saltzstein et al. 2001). The answer format was a four-point Likert scale from 1 (not satisfied) to 4 (very satisfied).

Individual-oriented working time flexibility: Individual-oriented working time flexibility was measured using three items from the control over work time scale by Valcour (2007) in an adapted version of the German translation by Becker (2012). An example item is: "How much control do you have over when you begin and end each workday?" Items could be answered on a five-point Likert scale from 1 (very little control) to 5 (very high control). Internal consistency (Cronbach's alpha) in the present sample was 0.68 . This value corresponds to the magnitude of internal consistency determined in other studies (Valcour 2007; Becker 2012) and results from the breadth of the content of the construct.

Organization-oriented working time flexibility: To measure organization-oriented working time flexibility, we used an item that captures the frequency of organization-determined changes in working time. It reads as follows: "How often do your working hours change in response to operational requirements?" The answer possibilities were never (1), rarely (2), sometimes (3), and often (4).

Segmentation preference: The preference for segmentation of work and private life was operationalized using three items from the segmentation preference scale developed by Kreiner (2006), which were adapted and translated into German (see, e.g., Peters et al. 2014). An example is: "It is important for me not to have to think about work in my free time." The answer format was a five-point Likert scale from "disagree" to "fully agree." The internal consistency of the scale in this sample can be considered good $(\alpha=0.83)$.

Control variables: Studies have shown associations between gender, age, and the presence of children with work-life balance (e.g., McNamara et al. 2013; Becker 2012). Therefore, gender, age, level of education, and whether children lived in the household were included in the calculation as control variables. Since some studies have additionally found an effect of having a supervisory role (Jacobshagen et al. 2005) and weekly working hours (Mc Namara et al. 2013) on one's work-life balance, we included these as control variables. Furthermore, to account for structural working conditions, we controlled for occupational sector (KldB 2010: Bundesagentur für Arbeit 2015), with the largest sector (commercial and company-related service occupations) as the reference category. All control variables were dummy-coded.

\section{Results}

\subsection{Descriptive results}

The mean values, standard deviations, and intercorrelations of the included variables are shown in Table 1. All study variables correlate significantly in the predicted directions. In particular, there are significant correlations between the criterion variable work-life balance and both individual- 
Table 1 Means, Standard Deviations and Correlations of Study Variables

Tab. 1 Mittelwerte, Standardabweichungen und Korrelationen der Studienvariablen

\begin{tabular}{|c|c|c|c|c|c|c|c|c|c|c|c|}
\hline Variable & $\mathrm{M}$ & $\mathrm{SD}$ & 1 & 2 & 3 & 4 & 5 & 6 & 7 & 8 & 9 \\
\hline 1. Gender & 0.50 & 0.50 & - & - & - & - & - & - & - & - & - \\
\hline 2. Age & 45.9 & 10.7 & $-0.05^{*}$ & - & - & - & - & - & - & - & - \\
\hline 3. Children & 0.35 & 0.48 & 0.02 & $-0.23 *$ & - & - & - & - & - & - & - \\
\hline 4. Education & 0.47 & 0.50 & $0.06^{*}$ & $0.08 *$ & $0.03 *$ & - & - & - & - & - & - \\
\hline 5. Supervisory role & 0.34 & 0.47 & $0.13 *$ & $0.04 *$ & $0.03 *$ & $0.14 *$ & - & - & - & - & - \\
\hline $\begin{array}{l}\text { 6. Weekly working } \\
\text { hours }\end{array}$ & 39.00 & 10.90 & $0.40^{*}$ & -0.00 & $-0.09 *$ & $0.16^{*}$ & $0.24 *$ & - & - & - & - \\
\hline $\begin{array}{l}\text { 7. Individual-oriented } \\
\text { flexibility }\end{array}$ & 3.28 & 1.11 & $0.11 *$ & 0.01 & $0.06^{*}$ & $0.14 *$ & $0.12 *$ & $0.06^{*}$ & - & - & - \\
\hline $\begin{array}{l}\text { 8. Organization-ori- } \\
\text { ented flexibility }\end{array}$ & 2.17 & 1.06 & 0.01 & -0.01 & -0.01 & $0.07 *$ & $0.11 *$ & $0.12 *$ & $-0.11^{*}$ & - & - \\
\hline $\begin{array}{l}\text { 9. Segmentation prefer- } \\
\text { ence }\end{array}$ & 3.85 & 1.12 & -0.01 & $-0.07 *$ & 0.02 & $-0.05^{*}$ & $-0.04 *$ & -0.00 & $-0.04 *$ & $-0.07 *$ & - \\
\hline 10. Work-life balance & 3.01 & 0.80 & $0.04 *$ & $0.05 *$ & 0.01 & $-0.04 *$ & $-0.05^{*}$ & $-0.24 *$ & $0.24 *$ & $-0.23 *$ & $-0.06^{*}$ \\
\hline
\end{tabular}

Note. $N=17,921$; gender: $1=$ male; children: $1=$ children under age 18 living in household, education: $1=$ high; supervisory role: $1=$ yes; $* p<0.001$

Table 2 Results of Hierarchical Regression Analyses for Work-Life Balance

Tab. 2 Ergebnisse der Hierarchischen Regressionsanalyse für Work-Life-Balance

\begin{tabular}{|c|c|c|c|c|}
\hline & $\begin{array}{l}\text { Model 1 } \\
\beta\end{array}$ & $\begin{array}{l}\text { Model } 2 \\
\beta\end{array}$ & $\begin{array}{l}\text { Model } 3 \\
\beta\end{array}$ & $\begin{array}{l}\text { Model } 4 \\
\beta\end{array}$ \\
\hline \multicolumn{5}{|l|}{ Control variables } \\
\hline Age & $0.05^{*}$ & $0.04 *$ & $0.04 *$ & $0.04 *$ \\
\hline Gender & $0.05 *$ & $0.04 *$ & $0.04 *$ & $0.04 *$ \\
\hline Children & -0.00 & -0.03 & -0.02 & -0.02 \\
\hline Education & -0.00 & $-0.03 *$ & $-0.03 *$ & $-0.03^{*}$ \\
\hline Supervisory role & 0.01 & 0.00 & -0.00 & -0.00 \\
\hline Weekly working hours & $-0.27 *$ & $-0.24 *$ & $-0.24 *$ & -0.24 \\
\hline \multicolumn{5}{|c|}{$\begin{array}{l}\text { Occupational sector } \\
\text { (ref. cat.: commercial and company-related service occupations) }\end{array}$} \\
\hline Production occupations & -0.02 & 0.01 & 0.01 & 0.01 \\
\hline Person-related service occupations & $-0.10^{*}$ & 0.02 & 0.02 & 0.02 \\
\hline IT- and scientific service occupations & -0.00 & -0.01 & -0.01 & -0.01 \\
\hline Other economic service occupations & $-0.07 *$ & -0.00 & -0.00 & -0.00 \\
\hline \multicolumn{5}{|l|}{ Flexibility } \\
\hline Individual-oriented flexibility & - & $0.24 *$ & $0.23 *$ & $0.23 *$ \\
\hline Organization-oriented flexibility & - & $-0.17 *$ & $-0.17 *$ & $-0.17 *$ \\
\hline \multicolumn{5}{|l|}{ Segmentation } \\
\hline Segmentation preference & - & - & $-0.06^{*}$ & $-0.06^{*}$ \\
\hline \multicolumn{5}{|l|}{ Interactions } \\
\hline $\begin{array}{l}\text { Individual-oriented flexibil- } \\
\text { ity } \times \text { segmentation preference }\end{array}$ & - & - & - & $0.03 *$ \\
\hline $\begin{array}{l}\text { Organization-oriented flexibil- } \\
\text { ity } \times \text { segmentation preference }\end{array}$ & - & - & - & $-0.04 *$ \\
\hline $\mathrm{R}^{2}$ & 0.07 & 0.15 & 0.15 & 0.16 \\
\hline$\Delta \mathrm{R}^{2}$ & $0.07 *$ & $0.08 *$ & $0.00 *$ & $0.00 *$ \\
\hline
\end{tabular}

Note. $N=17,525 ; * p<0.001$ oriented working time flexibility and organization-oriented working time flexibility.

\subsection{Hypotheses testing}

The results of the hierarchical moderated regression analysis are summarized in Table 2. Hypothesis 1, stating that individual-oriented flexibility is positively related to work- 


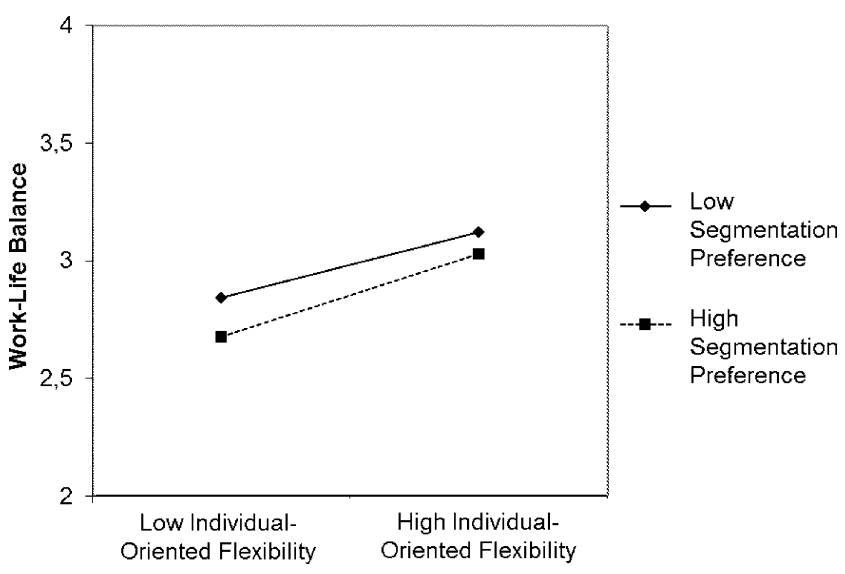

Fig. 2 Segmentation preference moderates the relationship of individual-oriented working time flexibility and work-life balance

Abb. 2 Segmentationspräferenz moderiert den Zusammenhang von individuumsbezogener Arbeitszeitflexibilität und Work-Life-Balance



Fig. 3 Segmentation preference moderates the relationship of organization-oriented working time flexibility and work-life balance

Abb. 3 Segmentationspräferenz moderiert den Zusammenhang von betriebsbezogener Arbeitszeitflexibilität und Work-Life-Balance

life balance, could be confirmed. The same is true for Hypothesis 2 , which expected organization-oriented working time flexibility to be negatively related to work-life balance. Interestingly, working time flexibility explains a larger proportion of variance in work-life balance $(8 \%)$ than demographic control variables $(<2 \%$, excluding weekly working hours).

With regard to the moderating effect of segmentation preference, both hypotheses could be confirmed. Segmentation preference strengthened both the positive relationship between individual-oriented working time flexibility and work-life balance (Hypothesis 3) and the negative relationship between organization-oriented working time flexibility and work-life balance. The simple slopes for segmentation preference at one standard deviation above and below the mean are depicted in Fig. 2 and 3. Simple slope analyses (Aiken and West 1991; Robinson et al. 2013) confirmed the significant interaction. In both cases, the regression lines for those with high and those with low segmentation preference differed significantly (individual-oriented working time flexibility: $t(17,649)=6.56, p<0.01$; organization-oriented working time flexibility: $t(17,795)=7.22$, $p<0.01)$. In line with our hypotheses, individual-oriented working time flexibility tends to have a slightly stronger positive association with work-life balance among those with a high segmentation preference than among those with a low segmentation preference. In addition, organization-oriented working time flexibility seems to be slightly stronger negatively associated with work-life balance for those with higher segmentation preference than for those with lower segmentation preference. However, in spite of the statistical significance, both moderating effects are very small and therefore cannot meaningfully contribute to an explanation of variance in work-life balance.

Apart from the abovementioned analyses using unweighted data, all analyses were additionally performed with a weighted data set. All participants received a weighting factor calculated on the basis of the probability of selection and calibrated to the German microcensus to ensure representativeness of the sample (Häring et al. 2016). These calculations showed no differences in the significant relationships and the explanation of variance, which suggests a high level of robustness and generalizability of the effects found.

\section{Discussion}

Using data of a large and representative sample of the German working population, the present study showed that individual-oriented working time flexibility is positively associated with work-life balance and that organization-oriented working time flexibility is negatively related with work-life balance. These findings are in line with earlier research and propositions (e.g., Kossek and Michel 2011), which we could now confirm to be generalizable to most of the German workforce. Previous studies found the general availability of flexibility to be less strongly related to workfamily outcomes than flexibility options directly linked to the family context (Allen et al. 2014). However, our data provides evidence suggesting that working time flexibility is a considerable factor in terms of the more general outcome work-life balance. In our study, working time flexibility plays a far larger role for work-life balance than socio-demographic aspects or the occupation itself. This underlines the importance of working conditions. Thus, individual-oriented and organization-oriented working time flexibility represent important contextual resources and demands that may drive processes at the work-home interface, as proposed in the work-home resources model (ten Brummelhuis and Bakker 2012). 
Temporal requirements, such as short notice changes in working hours and working overtime, complicate a clear separation of work and private life, thus running counter to the personal attitudes of those who have a strong preference for segmentation. However, our findings suggest that segmenters seem to suffer only marginally more, if at all, from limitations to individual-oriented working time flexibility and from high organization-oriented working time flexibility than integrators. Segmenters and integrators do not differ in their work-life balance when they have the ability to control their work-private life boundaries, that is, when individual-oriented working time flexibility is high or organization-oriented flexibility is low. These conditions enable segmenters and integrators alike to enact their preferred boundary management strategy. Furthermore, in line with earlier research (cf. Allen et al. 2014), we only find a very small direct relationship of segmentation preference and work-life balance. This indicates that-compared to working time arrangements-employees' preferences regarding the integration or segmentation of life domains hardly contribute to their work-life balance.

\subsection{Limitations and future research}

Some limitations of the present study have to be acknowledged. Since it is a cross-sectional study without multiple measurement or manipulation, no causal statements about the directions of effects can be made. In addition, all analyses are based on self-reported data collected through standardized interviews. Additional objective or multi-source measurements could enable more reliable statements and overcome the problem of common-method bias. Given the large sample size, very small relationships between variables become statistically significant. Although we applied a $0.1 \%$ alpha level, the practical relevance (e.g., of the moderating effects) might be limited.

Further, it should be noted that temporal flexibility is operationalized very differently in research. We limited the measurement of organizational-oriented working time flexibility to one item reflecting organization-determined changes in working time. Although this reflects the most important aspect of organization-oriented working time flexibility, it neglects other working time-related aspects (duration and timing) that may be part of the whole construct. Further, no validity information is available for this item. The same is true for the outcome variable worklife balance. Although work-life balance is measured with a single item in many studies (e.g., Ellwart and Konradt 2011; Lunau et al. 2014), the wording used is inconsistent. Thus, comparability remains unclear. As a result, when interpreting the results in the context of other research, the operationalizations of working time flexibility and worklife balance have to be taken into account. In future re- search, both organization-oriented flexibility and work-life balance should be measured with validated scales.

Although our overall understanding of the impact of working time flexibility is improving, several other research questions remain open. For example, against the background of work becoming increasingly flexible-not only in terms of working time but also in terms of workplace and work tasks - future studies should investigate the effects of these increasing flexibility options and requirements on employees' work-life balance and on their wellbeing and health. Further, it would be exciting to investigate actual segmentation possibilities in order to examine the interaction between preference and reality in the context of flexible work and work-life balance. Examining the extent of fit between preferences and possibilities could help us understand the effects of self-selection into certain jobs as well as turnover intentions. Based on person-environment fit theories, some studies already revealed interesting findings in this context. For example, Peters et al. (2014) found leaders' work-life balance in the presence of family-towork conflict to be highest when high segmentation preferences meet high segmentation possibilities. Further, Kreiner (2006) found asymmetric results of fit effects, in a way that segmentation possibilities that exceeded the preferences even further decreased the work-home conflict. Thus, future research could explore the interplay of segmentation preferences and possibilities in the context of increasingly flexible work. In addition, according to the extended job-demands resources model (Xanthopoulou et al. 2007) and the work-home-resources model (ten Brummelhuis and Bakker 2012), other personal resources such as self-efficacy, selfesteem, and optimism may mediate the relation between both individual-oriented and organization-oriented working time flexibility and work-life balance. Thus, future research should evaluate the mediating role of personal resources in this context. Moreover, other research has shown the moderating role of personal resources between job demands and well-being (e.g., Mäkikangas and Kinnunen 2003; Pierce and Gardner 2004). To contribute to a broader understanding of the work-home interface, future research on individual-oriented as well as organization-oriented working time flexibility and work-life balance should therefore also examine the moderating role of personal resources.

\subsection{Implications}

All employees-regardless of their segmentation preference-benefit from well-designed individual-oriented flexibility, even if segmenters tend to benefit a little more. A high level of organization-oriented working time flexibility and a lack of individual-oriented working time flexibility are related to disruptions in work-life balance among segmenters and integrators alike. Thus, giving employees control over 
their working time and keeping organization-oriented temporal flexibility requirements to a minimum is important to help employees maintain a good work-life balance. Employees' working time control can be promoted by flexible working time arrangements. If employees can decide when to start and end work, when to take their breaks, or whether or not to work from home (within a considerable organizatonal framework), their sense of working time control should increase. In addition, organizations should support employees in taking responsibility for their working time control. In contrast, flexible working time arrangements should not be used to cope with time pressure and high workload. Morover, short notice shifts in working tasks and hours will counteract perceived working time control.

Our findings indicate that flexibility conditions regarding working time are more relevant than employees' personal situation or individual attitude when it comes to worklife balance. However, special attention should be paid to employees with high segmentation preferences, because they might suffer more from reduced individual-oriented working time flexibility and from increased organizationoriented working time flexibility. For example, Brauner et al. (2018) found that segmenters whose job does not allow for the separation of work and private life have more health problems - especially fatigue - than other employees. These research findings regarding segmentation preferences should be communicated to both employers and employees. It is important to consider the results of psychological studies on working time and wellbeing/work-lifebalance in the design of working time and, based on this, to develop limits and guidelines for work-related flexibility that allows for health-promoting work. This is particularly relevant for occupations in which organization-oriented working time flexibility is indispensable for the practice of the occupation, such as doctors, nurses, or caterers. The working time realities in such occupations, as well as the problems they entail for certain groups of employees (e.g., segmenters), should be clearly communicated in the context of career decision-making and occupational choices to give candidates a realistic idea of an occupation and to avoid later discontent.

\subsection{Outlook}

Increasing flexibility at work and its effect on employees' private life and health have been receiving more and more attention in current research. This is of great importance, because the rapidly changing working world is likely to require even more flexibility from employees. As more and more workers are expected to be available 24/7, to answer requests in real time, to work in virtual teams, and to lead remotely, the pressure to create flexible working time conditions will increase further. However, the question of how to design healthy work environments should always guide our research and the resulting practical recommendations. Our study aims to support the design of healthy work environments. In our study, we examined one aspect of flexibility by considering individual-oriented and organizationoriented working time flexibility. In addition, the interacting influence of other variables, in particular individual variables such as personality, attitudes, or values, must be taken into account to be able to paint a more complete picture. As it turns out, we need new, innovative, and individual answers to successfully intergrate work and private life against the background of a changing working world. Ultimately, this paper and future research should enable scientifically sound, healthy work arrangements.

Funding Open Access funding enabled and organized by Projekt DEAL.

Open Access This article is licensed under a Creative Commons Attribution 4.0 International License, which permits use, sharing, adaptation, distribution and reproduction in any medium or format, as long as you give appropriate credit to the original author(s) and the source, provide a link to the Creative Commons licence, and indicate if changes were made. The images or other third party material in this article are included in the article's Creative Commons licence, unless indicated otherwise in a credit line to the material. If material is not included in the article's Creative Commons licence and your intended use is not permitted by statutory regulation or exceeds the permitted use, you will need to obtain permission directly from the copyright holder. To view a copy of this licence, visit http://creativecommons.org/licenses/by/4. $0 /$.

\section{References}

Aiken LS, West SG (1991) Multiple regression: testing and interpreting interactions. SAGE, Newbury Park

Allen TD, Herst DEL, Bruck CS, Sutton M (2000) Consequences associated with work-to-family conflict: A review and agenda for future research. J Occup Health Psychol 5:278-308

Allen TD, Cho E, Meier LL (2014) Work-family boundary dynamics. Annu Rev Organ Psych 1:199-121. https://doi.org/10.1146/ annurev-orgpsych-031413-091330

Ammons SK (2013) Work-family boundary strategies: stability and alignment between preferred and enacted boundaries. J Vocat Behav 82:49-58

Amstad FT, Meier LL, Fasel U, Elfering A, Semmer NK (2011) A meta-analysis of work-family conflict and various outcomes with a special emphasis on cross-domain versus matching-domain relations. J Occup Health Psychol 16:151-169

Ashforth BE, Kreiner GE, Fugate M (2000) All in a day's work: boundaries and micro role transitions. Acad Manage Rev 25:472-491

Becker PR (2012) Work-life-Balance: Einflussfaktoren- Auswirkungen - Handlungsempfehlungen: Ein ressourcenbasierter Ansatz am Beispiel einer empirischen Untersuchung in der Industrie. Dissertation. Ruprecht-Karls-Universität, Heidelberg

Brauner C, Wöhrmann AM, Michel A (2018) BAuA-Arbeitszeitbefragung: Arbeitszeit-wünsche von Beschäftigten in Deutschland, 1st edn. Bundesanstalt für Arbeitsschutz und Arbeitsmedizin, Dortmund

ten Brummelhuis L, Bakker A (2012) A resource perspective on the work-home interface: the work-home resources model. Am Psychol 67:545-555 
Bundesagentur für Arbeit (2015) Klassifikation der Berufe 2010. Nürnberg: Bundesagentur für Arbeit. https://statistik.arbeitsagentur. de/Navigation/Statistik/Grundlagen/Klassifikation-der-Berufe/ KldB2010/KldB2010-Nav.html. Accessed 20 June 2020

Chung H, Lippe T (2018) Flexible working, work-life balance, and gender equality: Introduction. Soc Indic Res. https://doi.org/10. 1007/s11205-018-2025-x

Chung H, van der Horst M (2020) Flexible working and unpaid overtime in the UK: The role of gender, parental and occupational status. Soc Indic Res 151:495-520. https://doi.org/10.1007/s11205018-2028-7

Clark SC (2000) Work/family border theory: a new theory of work/ family balance. Hum Relat 53(6):747-770

Clarke MC, Koch LC, Hill EJ (2004) The work-family interface: differentiating balance and fit. Fam Consum Sci Res J 33:121-140

Costa G, Åkerstedt T, Nachreiner F, Baltiere F, Carvalhais J, Folkard S, Härmä M (2004) Flexible working hours, health, and well-being in Europe: some considerations from a SALTSA project. Chronobiol Int 21:831-844

Deci EL, Ryan RM, Gagné M, Leone DR, Usunov J, Kornazheva BP (2001) Need satisfaction, motivation, and well-being in the work organizations of a former eastern bloc country: A cross-cultural study of self-determination. Pers Soc Psychol B 27:930-942. https://doi.org/10.1177/0146167201278002

Derks D, Bakker AB, Peters P, van Wingerden P (2016) Work-related smartphone use, work-family conflict and family role performance: The role of segmentation preference. Hum Relat 69:1045-1068

Edwards JR, Rothbard NP (2000) Mechanisms linking work and family: clarifying the relationship between work and family constructs. Acad Manage Rev 25:178-199

Ellwart T, Konradt U (2011) Formative versus reflective measurement: an illustration using work-family balance. J Psychol 145:391-417

Greubel J, Arlinghaus A, Nachreiner F, Lombardi DA (2016) Higher risks when working unusual times? A cross-validation of the effects on safety, health, and work-life balance (PSYNDEXshort). Int Arch Occup Environ Health 89(8):1205-1214

Häring A, Schütz H, Gilberg R, Kleudgen M, Wöhrmann AM, Brenscheidt F (2016) Methodenbericht und Fragebogen zur BAuAArbeitszeitbefragung 2015. Bundesanstalt für Arbeitsschutz und Arbeitsmedizin (BAuA), Dortmund

Hobfoll SE (1989) Conservation of resources: A new attempt at conceptualizing stress. Am Psychol 44:513-524

Hünefeld L, Wöhrmann AM, Brauner C (2019) Arbeiten unter Druck: Arbeitsintensität, Arbeitszeitautonomie und Wohlbefinden von Beschäftigten in Deutschland. In: Griesbacher M, Hödl J, Muckenhuber J, Scaria-Braunstein K (eds) Intensivierung der Arbeit-Perspektiven auf Arbeitszeit und technologischen Wandel. New Academic Press, Wien, pp 73-86

Jacobshagen N, Amstad FT, Semmer NK, Kuster M (2005) Workfamily balance at top management level: Work-family conflict as a mediator of the relationship between stressors and strain. Z Arbeits Organisationspsychol 49:208-219

Janßen D, Nachreiner F (2004) Flexible Arbeitszeiten. Schriftenreihe der Bundesanstalt für Arbeitsschutz und Arbeitsmedizin. Bundesanstalt für Arbeitsschutz und Arbeitmedizin, Dortmund, Berlin, Dresden

Kossek EE, Michel JS (2011) Flexible work schedules. In: Zedeck S, Zedeck S( (ed) Building and developing the organization. APA handbook of industrial and organizational psychology, vol 1. American Psychological Association, Washington, DC, pp 535-572

Kossek EE, Lautsch BA, Eaton SC (2006) Telecommuting, control, and boundary management: correlates of policy use and practice, job control, and work-family effectiveness. J Vocat Behav 68:347-367
Kreiner GE (2006) Consequences of work-home segmentation or integration: a person-environment fit perspective. J Organ Behav 27:485-507

Kreiner GE, Hollensbe EC, Sheep ML (2009) Balancing borders and bridges: negotiating the work-home interface via boundary work tactics. Acad Manag J 52:704-730

Lott Y (2020) Does flexibility help employees switch off from work? Flexible working-time arrangements and cognitive work-tohome spillover for women and men in Germany. Soc Indic Res 151:471-494

Lott Y (2017) Stressed despite or because of flexible work arrangements? Flexible work arrangements, job pressure and work-tohome conflict for women and men in Germany. Working Paper Forschungsförderung 64

Lunau T, Bambra C, Eikemo TA, van der WEl KA, Dragano N (2014) A balancing act? Work-life balance, health and well-being in European welfare states. Eur J Public Health 24(3):422-427

Mäkikangas A, Kinnunen U (2003) Psychosocial work stressors and well-being: self- esteem and optimism as moderators in a oneyear longitudinal sample. Pers Individ Dif 35:537-557

Matthews RA, Barnes-Farrell JL (2010) Development and initial evaluation of an enhanced measure of boundary flexibility for the work and family domains. J Occup Health Psychol 15:330-346

McNamara TK, Pitt-Catsouphes M, Matz-Costa C, Braown M, Valcour M (2013) Across the continuum of satisfaction with work-family balance: Work hours, flexibility-fit, and work-family culture. Soc Sci Res 42:283-298. https://doi.org/10.1016/j. ssresearch.2012.10.002

Michel A, O'Shea D, Hoppe A (2015) Designing and evaluating resource-oriented interventions to enhance employee well-being and health. J Occup Organ Psychol 88:459-463

Michel JS, Mitchelson JK, Kotrba LM, LeBreton JM, Baltes BB (2009) A comparative test of work-family conflict models and critical examination of work-family linkages. J Vocat Behav 74:199-218

Nilsen W, Skipstein A, Østby KA, Mykletun A (2017) Examination of the double burden hypothesis - a systematic review of work-family conflict and sickness absence. Eur J Public Health 27(3):465-471

Nippert-Eng C (1996) Home and work: negotiating boundaries through everyday life. University Chicago, Chicago

Njip HH, Beckers DGJ, Geurts SAE, Tucker P, Kompier MAJ (2012) Systematic review on the association between employee worktime control and work-non-work balance, health and well-being, and job-related outcomes. Scand J Work Environ Health 34:299-313

Nohe C, Meier LL, Sonntag K, Michel A (2015) The chicken or the egg? A meta-analysis of panel studies of the relationship between work-family conflict and strain. J Appl Psychol 100:522-536

Park Y, Jex SM (2011) Work-home boundary management using communication and information technology. Int J Stress Manage 18:133-152

Peters A, Michel A, Sonntag K (2014) Konflikte zwischen Privat-und Berufsleben bei Führungskräften. Z Arbeits Organisationspsychol 48:64-79

Pierce JL, Gardner DG (2004) Self-esteem within the work and organizational context: a review of the organizational-based self-esteem literature. J Manage 30:591-622

Rexroth M, Michel A, Bosch C (2017) Promoting well-being by teaching employees how to segment their life domains-effects of an online-based mindfulness intervention. Z Arbeits Organisationspsychol 61:197-212

Robinson CD, Tomek S, Schumacker RE (2013) Tests of moderation effects: difference in simple slopes versus the interaction term. Multiple Lin Regress. Viewpoints 39:16-24

Rothbard NP, Phillips KW, Dumas TL (2005) Managing multiple roles: work-family policies and individuals' desires for segmentation. Organ Sci 16:243-258 
Saltzstein AL, Ting Y, Saltzstein GH (2001) Work-family balance and job satisfaction: the impact of family-friendly policies on attitudes of federal government employees. Public Adm Rev 61:452-457

Seitz J, Rigotti T (2018) How do differing degrees of working-time autonomy and overtime affect worker well-being? A multilevel approach using data from the German socio-economic panel (SOEP). Ger J Hum Resour Manage 32(3-4):177-194

Vahle-Hinz T, Bamberg E (2009) Flexibilität und Verfügbarkeit durch Rufbereitschaft - die Folgen für Gesundheit und Wohlbefinden. Arbeit 18:327-339
Valcour M (2007) Work-based resources as moderators of the relationship between work hours and satisfaction with work-family balance. J Appl Psychol 92:1512-1523

Wöhrmann AM (2016) Psychische Gesundheit in der Arbeitswelt Work-Life-Balance. Dortmund: Bundesanstalt für Arbeitsschutz und Arbeitsmedizin

Xanthopoulou D, Bakker AB, Demerouti E, Schaufeli WB (2007) The role of personal resources in the job demands-resources model. Int J Stress Manag 14(2):121-141 